\title{
The necessity for measurement of left atrial pressure after cardiac valve surgery ${ }^{1}$
}

\author{
C. L. SAR IN, E. YALAV,A. J. CLEMENT, and \\ M. V. B R A I M B R I D G E \\ Department of Cardiothoracic Surgery, St. Thomas Hospital, London, S.E.1
}

\begin{abstract}
Left and right atrial pressures were monitored in 100 patients undergoing open heart surgery for acquired valvular disease of the heart at St. Thomas' Hospital. The right atrial pressure bore no constant relationship to the left atrial pressure in $61 \%$ of the patients and there was no reliable way of deducing left atrial pressure from the right. We believe that it is imperative to measure both right and left atrial pressures if post-operative management after cardiac valve surgery is to be effective. There has been no instance of pulmonary oedema or postperfusion syndrome in our practice since its introduction.
\end{abstract}

The maintenance of an optimum cardiac output is the main aim of post-operative care in a cardiac surgical patient. Cardiac output is a function of stroke volume and heart rate. After cardiac surgery the heart rate can usually be kept at an adequate level by pacemaking or by chronotropic drugs such as isoprenaline. The stroke volume depends in part on the filling pressure and in part on myocardial contractility, which can be improved by inotropic agents but is largely determined by the pre-operative condition of the patient.

The stroke volume of the right ventricle is directly related to the central venous pressure (the right atrial pressure), and the output of the left heart is similarly related to the left atrial pressure. The value of the measurement of central venous pressure in regulating blood transfusion in the post-operative care of a cardiac surgery patient has been accepted (Sykes, 1963; Braimbridge and Ghadiali, 1965 ; Kirklin and Rastelli, 1965) and is universally employed. The importance of measuring the left atrial pressure has been recognized (Fishman, Hutchinson, and Roe, 1966; Keddie, Provan, and Austen, 1966) but has not been generally adopted, mainly because it is believed that right and left atrial pressures are closely related. This may be true in health but in acquired valvular disease, where one side of the heart may be more affected than the other, the normal rela-

1 Based on a paper presented at the annual meeting of the Society of Thoracic and Cardiovascular Surgeons of Great Britain and Ireland at Belfast (September 1969) tionship between right and left atrial pressures may not exist.

At St. Thomas' Hospital we have been using right and left atrial presures as a guide to the postoperative management of blood or fluid replacement in patients undergoing valve surgery. It is the purpose of this communication to analyse the data on the inter-relationship of right and left atrial pressures in these patients.

\section{METHODS AND MATERIALS}

One hundred consecutive patients undergoing valve replacement or repair with the aid of cardiopulmonary bypass constitute the clinical material. The diagnoses and surgical procedures carried out in these patients are shown in Table I.

Central venous pressure was monitored through a 24 inch long PVC $^{2}$ suction catheter advanced along the saphenous vein from the saphenofemoral junction to a point where the tip lay high in the inferior vena cava close to the right atrium. At the end of the operation a fine purse-string suture was placed in the left atrial wall close to the right superior pulmonary vein. A no. 28 Teflon catheter was passed into the left atrium through a 17 gauge hypodermic needle and the purse-string was tied. The same needle was used for passing the catheter through the chest wall, where it was carefully fixed to the skin. Both catheters were connected to pressure transducers. The mean pressure could be read off electromanometric dials and the wave form studied on an oscilloscope.

The mean right and left atrial pressures were

${ }^{2}$ Supplied by Portland Plastic Ltd. 
T A B L E I

DIAGNOSIS AND TREATMENT IN 100 PATIENTS WITH VALVULAR HEART DISEASE USED IN THIS STUDY

\begin{tabular}{|c|c|c|c|c|c|c|c|c|c|c|c|c|}
\hline \multirow{2}{*}{\multicolumn{3}{|c|}{ Surgical Treatment }} & \multirow[b]{2}{*}{ No. } & \multicolumn{3}{|c|}{ Aortic Valve Disease } & \multicolumn{3}{|c|}{ Mitral Valve Disease } & \multicolumn{3}{|c|}{ Tricuspid Valve Disease } \\
\hline & & & & A.S. & A.I. & $\begin{array}{l}\text { Com- } \\
\text { bined }\end{array}$ & M.S. & M.I. & $\begin{array}{l}\text { Com- } \\
\text { bined }\end{array}$ & T.S. & T.I. & $\begin{array}{l}\text { Com- } \\
\text { bined }\end{array}$ \\
\hline \multicolumn{3}{|c|}{ 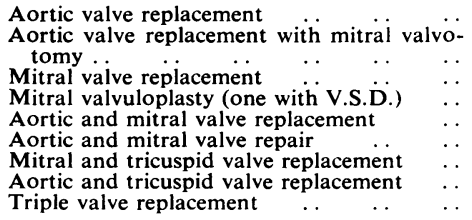 } & $\begin{array}{r}30 \\
2 \\
29 \\
5 \\
19 \\
1 \\
7 \\
1 \\
6\end{array}$ & $\begin{array}{l}5 \\
- \\
- \\
- \\
- \\
-\end{array}$ & $\frac{14}{\frac{1}{11}}$ & $\begin{array}{l}11 \\
\frac{1}{6} \\
\frac{6}{-} \\
\frac{1}{1}\end{array}$ & $\begin{array}{l}- \\
2 \\
= \\
= \\
- \\
-\end{array}$ & $\begin{array}{r}4 \\
- \\
9 \\
5 \\
13 \\
1 \\
4 \\
1 \\
3\end{array}$ & $\begin{array}{c}4 \\
\frac{19}{6} \\
\frac{6}{3} \\
\frac{3}{3}\end{array}$ & $\begin{array}{l}- \\
- \\
- \\
- \\
- \\
- \\
-\end{array}$ & $\begin{array}{c}1 \\
\overline{11} \\
\frac{6}{5} \\
1 \\
5\end{array}$ & $\begin{array}{l}- \\
\frac{-}{1} \\
\frac{-}{2} \\
\frac{1}{1}\end{array}$ \\
\hline \multicolumn{3}{|c|}{ Total } & 100 & & & & & & & & & \\
\hline
\end{tabular}

recorded at frequent intervals and the records taken during the first 24 hours of the post-operative period were analysed. The left atrial catheter was flushed with heparinized normal saline every half an hour and both catheters were removed at the end of 48 hours.

Blood or plasma was transfused until an adequate cardiac output was achieved, the left atrial pressure reached $12 \mathrm{~mm}$. $\mathrm{Hg}$ or tricuspid incompetence developed. An adequate cardiac output was defined as one producing a urine volume of $0.5 \mathrm{ml} . / \mathrm{kg}$. $/$ hour and a warm periphery with dilated veins and a minimal systolic arterial pressure of $90 \mathrm{~mm}$. $\mathrm{Hg}$.

The sternal angle was the reference point for measurement of pressure in this study.

\section{RESULTS}

TYPES OF PRESSURE RELATIONSHIP In the analysis of the relationship between right and left atrial pressure, the general trend over the 24 -hour period rather than the absolute figures have been taken into consideration. Four separate types of pressure relationships have been seen in these patients.

Type 1 Curves of the right and left atrial pressure showed parallel changes and the left atrial pressure never exceeded the right atrial pressure by more than $3 \mathrm{~mm}$. $\mathrm{Hg}$ (Fig. 1). This is generally regarded as the normal relationship.

Type 2 Curves of the right and left atrial pressures showed parallel changes, but the left atrial pressure was more than $3 \mathrm{~mm}$. $\mathrm{Hg}$ higher than the right atrial pressure at all times (Fig. 2).

Type 3 The left atrial pressure was higher than the right atrial pressure, but the two pressures did not run parallel. At times these were as close as in type 1 and at other times as widely separated as in type 2 (Fig. 3). The left atrial pressure was consistently higher than the right atrial pressure, but the difference varied between $2 \mathrm{~mm}$. $\mathrm{Hg}$ and 7-9 $\mathrm{mm}$. $\mathrm{Hg}$ at different times in the same patient. The relationship between the two filling pressures was totally unpredictable.

Type 4 The right atrial pressure was higher than the left atrial pressure most of the time (Fig. 4).

INCIDENCE OF TYPES OF PRESSURE RELATIONSHIP The 'normal' relationship between the atrial pressure (type 1) was found in only $28 \%$ of the patients. On the whole, low levels of left and right atrial pressure were needed to attain a satisfactory cardiac output in patients with the type 1 atrial pressure curve.

\section{T A B L E I I}

VARIOUS TYPES OF ATRIAL PRESSURE CURVES IN RELATION TO SURGICAL PROCEDURE CARRIED OUT

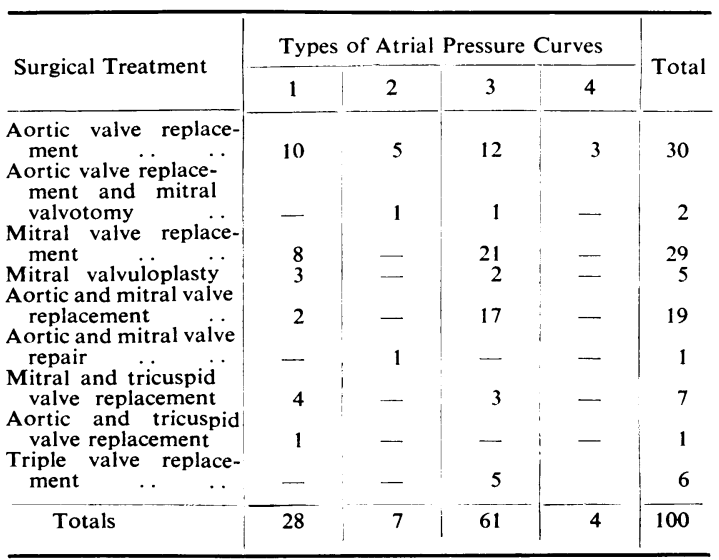



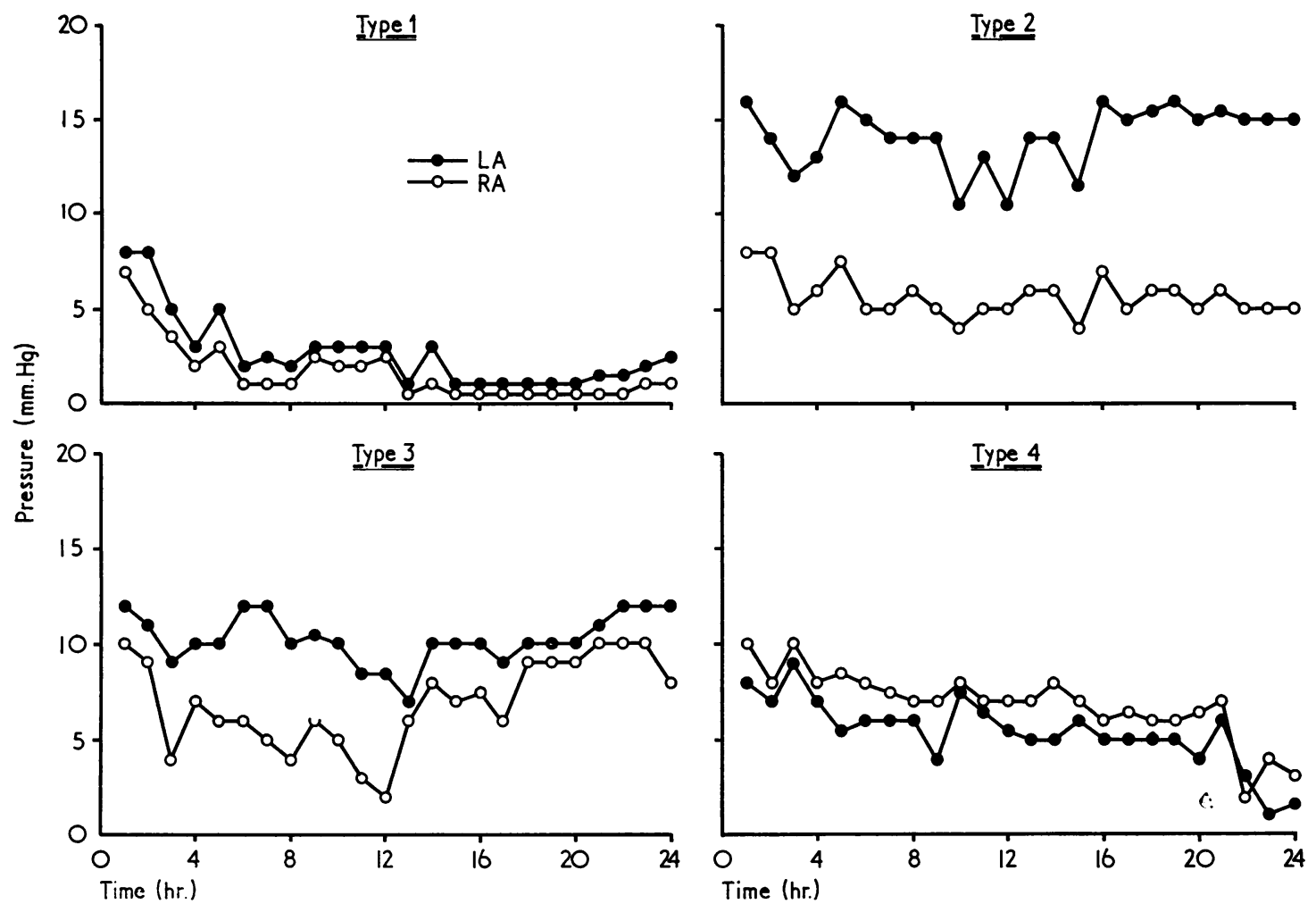

FIG. 1. Right and left atrial pressures over a 24-hour period in a patient following aortic valve replacement. In type 1 the left atrial (L.A.) pressure is higher than the right atrial (R.A.) pressure by not more then $3 \mathrm{~mm}$. Hg.

FIG. 2. Right and left atrial pressures over a 24-hour period in a patient following aortic and mitral valve repair. Left atrial pressure in type 2 is consistently higher than right atrial pressure by more than $3 \mathrm{~mm} . \mathrm{Hg}$. Changes in the two pressures are roughly parallel.

FIG. 3. Right and left atrial pressures over a period of 24 hours in a patient following aortic and mitral valve replacement. Left atrial pressure in type 3 is higher than the right atrial pressure, but the relation between the two is irregular and unpredictable.

FIG. 4. Right and left atrial pressures over a 24-hour period following mitral valve replacement. Patient had a mean pulmonary artery pressure of $55 \mathrm{~mm}$. Hg. Right atrial pressure in type 4 is higher than the left atrial pressure.

Type 2 was seen in only $7 \%$ of cases. All these patients had an aortic valve replacement or repair and two of these had mitral valvuloplasty in addition.

In $61 \%$ of the patients the inter-relationship between the atrial pressures was as type 3 .

In $4 \%$ of the patients the right atrial pressure was consistently higher than the left atrial pressure (type 4). All these patients had pulmonary hypertension of varying degrees, although not all the patients with pulmonary hypertension showed this pattern.

COMPARISON WITH SURGICAL PROCEDURE The surgical procedure was compared with the types of atrial pressure curves in Table II.
Attempts were made to correlate the type of atrial pressure curve, the cause of the valvular lesion (congenital, rheumatic, or ischaemic), the type of surgical treatment, the heart rhythm, and associated uncorrected valve disease (e.g., functional tricuspid incompetence or mild mitral or aortic valve disease). No acceptable way of predicting the type of atrial pressure curve likely to be encountered in the post-operative period was found.

COMPLICATIONS OF LEFT ATRIAL PRESSURE MEASUREMENT There were no fatal complications associated with measurement of left atrial pressure in this way. In one patient the needle for passing the catheter through the chest wall in- 
advertently damaged the internal mammary artery and the patient had to be re-opened for bleeding. This was the only complication encountered with measurement of left atrial pressure.

\section{DISCUSSION}

The filling pressure of the ventricle most under stress is crucial for the maintenance of an optimal cardiac output after cardiac surgery. The filling pressure depends in part on the blood volume, the regulation of which is therefore important in postoperative management. Actual measurement of the circulating blood volume involves techniques such as the Volumetron that are largely irrelevant after cardiac surgery because the volume of the vascular compartment, and hence the filling pressure, varies markedly from time to time as areas such as the skin and viscera are opened up or bypassed. This is the reason why no quantitative relationship exists between the measured circulating blood volume and the central venous pressure (Keddie et al., 1966).

The contractility of each ventricle may vary independently of the other, the stroke volume of the right heart being related to the right atrial pressure and the stroke volume of the left heart being similarly related to the left atrial pressure. Because the output of both ventricles must be the same, the ventricles may operate at widely different filling pressures. Both atrial pressures need to be measured if the function of each ventricle is to be separately monitored and the maximum output achieved for the minimum filling pressure.

Data in the literature are scanty on the subject of the inter-relationship of atrial pressures. Berglund (1954), in his studies in dogs at thoracotomy, studied the inter-relationship between the right and left atrial pressures. He showed that the left atrial pressure rose more steeply than the right atrial pressure after transfusion of blood or other fluid.

Similar findings were obtained by Theye and Moffitt (1962), who studied the effect of blood transfusion on atrial pressures at thoracotomy in three patients after correction of their atrial septal defects with the aid of cardiopulmonary bypass. Fordham and Resnekov (1967) studied the left atrial pressure in six patients after aortic valve replacement. In three they found a relationship between the right and left atrial pressures, as in type 1 in the present study, and in three no definite relationship existed, as in type 3 in the present study.

No study of the relationship between left and right atrial pressures over as long a period of time as the present series has yet been reported. At St. Thomas' Hospital after cardiac surgery blood or plasma is transfused until either a satisfactory cardiac output is attained or the left atrial pressure exceeds $12 \mathrm{~mm} . \mathrm{Hg}$ or the patient develops tricuspid incompetence. The clinical indices of a satisfactory cardiac output are a warm periphery, a urinary output of at least $0.5 \mathrm{ml} . / \mathrm{kg}$ body weight/hour, and a systolic arterial pressure above $90 \mathrm{~mm}$. $\mathrm{Hg}$. If the cardiac output is still not satisfactory when the left atrial pressure has reached $12 \mathrm{~mm}$. $\mathrm{Hg}$ from the sternal angle, this pressure is not exceeded but measures are taken to improve the stroke volume or heart rate (isoprenaline, pacemaker, glucagon, glucose, and insulin, etc.). Routine maintenance of a high level of right atrial pressure, as suggested by Kirklin and Rastelli (1965), Fordham and Resnekov (1967), and Wooler and McMillan (1968), is not, in our opinion, desirable because a satisfactory cardiac output is often seen in patients whose right atrial pressure is as low as $2 \mathrm{~mm}$. $\mathrm{Hg}$. Any attempt to raise the atrial pressure in such patients requires a large amount of blood and is unnecessary in that a cardiac output that is providing good tissue perfusion is all that is required after cardiac surgery, and trying to achieve a maximal output increases cardiac work unnecessarily. We have also noticed that the descending limb of the Starling's curve may start at a left atrial pressure of $5 \mathrm{~mm}$. $\mathrm{Hg}$ in some patients with a low cardiac output (Bradley, 1969).

It is evident from this study that the 'normal' atrial pressure relationship exists in only $28 \%$ of the cases undergoing surgery for valvular heart disease. No means of anticipating the type of atrial pressure relationships in the post-operative phase is apparent. If measurement of the left atrial pressure is omitted and reliance is placed on the right atrial pressure alone, 'pump lung' and pulmonary oedema may follow too high a level of left atrial pressure or a low cardiac output be the sequel of too low a pressure. Since the introduction of this technique in our practice we have not encountered a single case of pulmonary oedema or 'pump lung' syndrome.

The authors would like to thank the nursing staff of the Intensive Care Unit at St. Thomas' Hospital for careful records of the pressures, and $\mathbf{M r}$. $\mathbf{M}$. Korbel for preparation of the illustrations. 


\section{REFERENCES}

Berglund, E. (1954).Ventricular function. VI. Balance of left and right ventricular output: relation between left and right atrial pressures. Amer. J. Physiol., 178, 381.

Bradley, R. L, (1969). Personal communication.

Braimbridge, M. V.. and Ghadiali, P. E. (1965). Postoperative Cardiac Care, pp. 11-14. Blackwell Scientific Publications, Oxford.

Fishman, N. H., Hutchinson, J. C., and Roe, B. B. (1966). Controlled atrial hypertension: A method for supporting cardiac output following open-heart surgery. J. thorac. cardiovasc. Surg., 52, 777.

Fordham, R. M. M., and Resnekov, L. (1967). Circulatory changes resulting from increasing the venous filling pressure by trans. fusion following aortic valve homograft replacement. Cardiovasc. Res., 1, 159.
Keddie, N. C., Provan, J. L., and Austen, W. G. (1966). Central venous pressure, blood volume determinations, and the effects of vasoactive drugs in hypovolemic shock. Surgery, 60, 427.

Kirklin, J. W., and Rastelli, G. (1965). Low cardiac output after open intracardiac operations. Progress in Cardio-vascular Disease.

Sykes, M. K. (1963). Venous pressure as a clinical indication of adequacy of transfusion. Ann. roy. Coll. Surg. Engl., 33, 185.

Theye, R. A., and Moffitt, E. A. (1962). Blood transfusion therapy during anaesthesia and operation. Anaesth. Analg. Curr. Res., 41, 354.

Wooler, C. H., and McMillan, I. K. R. (1968). Rheumatic mitral valve disease. In Modern Trends in Cardiac Surgery 2, ed. Wooler, G.H., and Aberdeen, E., p. 75. Butterworths, London. 